Low-grade oils and fats: effect of several impurities on biodiesel production over sulfonic acid heterogeneous catalysts

Gabriel Morales ${ }^{\mathrm{a}}$, L. Fernando Bautista*a, Juan A. Melero ${ }^{\mathrm{a}}$, Jose Iglesias ${ }^{\mathrm{b}}$, Rebeca Sánchez-Vázquez

${ }^{a}$ Department of Chemical and Environmental Technology. Universidad Rey Juan Carlos. C/ Tulipán s/n. E-28933. Móstoles. Madrid. Spain.

${ }^{\mathrm{b}}$ Department of Chemical and Energy Technology. Universidad Rey Juan Carlos. C/ Tulipán s/n. E-28933. Móstoles. Madrid. Spain.

\title{
Published on:
}

Bioresource Technology 102 (2011), 9571-9578

DOI: $\underline{\text { 10.1016/j.biortech.2011.07.082 }}$

*Corresponding author:

Luis Fernando Bautista, Department of Chemical and Environmental Technology, ESCET, Universidad Rey Juan Carlos. C/ Tulipán s/n. E-28933 Móstoles, Madrid, Spain.

Tel: [34] 914888501

Fax: [34] 916647490

e-mail: fernando.bautista@urjc.es 


\begin{abstract}
Different lipidic wastes and low-grade oils and fats have been characterized and evaluated as feedstocks for the acid-catalyzed production of FAME. The characterization of these materials has revealed significant contents of free fatty acids, $\mathrm{Na}, \mathrm{K}, \mathrm{Ca}, \mathrm{Mg}, \mathrm{P}$, unsaponifiable matter and humidity. Arenesulfonic acidfunctionalized SBA-15 silica catalyst has provided yields to FAME close to $80 \%$ in the simultaneous esterification-transesterification of the different feedstocks, regardless of their nature and properties, using methanol under the following reaction conditions: $160^{\circ} \mathrm{C}, 2 \mathrm{~h}, 30$ methanol to oil molar ratio, $8 \mathrm{wt} \%$ catalyst loading, and $2000 \mathrm{rpm}$ stirring rate. Nevertheless, reutilization of the catalyst is compromised by high levels of impurities, especially because of deactivation by strong interaction of unsaponifiable matter with the catalytic sites. The conditioning of these materials by aqueous washing in the presence of cationic-exchange resin Amberlyst-15, followed by a drying step, resulted in a lower deactivation of the catalyst.
\end{abstract}

Keywords: FAME; acid catalysis; arenesulfonic; mesostructured materials; waste oils and fats. 


\section{Introduction}

Transport sector currently accounts for over $30 \%$ of the total primary energy consumption in the European Union (EU) and is $98 \%$ dependent on fossil fuels. The EU is a net crude oil importer, with an increasing trend in oil dependency ratio ( $72.9 \%$ in 1999 and $83.5 \%$ in 2009. Source: Eurostat). One of the most important energy targets for the EU is thus the reduction of oil use and dependency. A recent EU Directive (2009/28/EC) establishes a 20\% target share of renewable energy in primary energy consumption by 2020 , with a $10 \%$ share of energy from renewable sources for transport. In turn, another EU Directive (2003/96/EC) allows the Member States exemptions or reductions on excise duties so as to promote biofuels, and consequently there is a growing interest for biofuels in Europe. In this context, biodiesel constitutes a renewable fuel that is almost compatible with commercial diesel engines and has clear environmental benefits relative to diesel fuel. Biodiesel consists of a mixture of fatty acid alkyl esters (FAAEs) obtained from renewable resources, such as vegetable oils and animal fats, by transesterification with methanol or ethanol in the presence of an acid or basic catalyst (Freedman et al., 1984). It can be synthesized from a variety of feedstocks, but refined vegetable oils (such as soybean, rapeseed, palm and others) are currently the primary industrial feedstock. The relatively high and unstable prices of these food-grade raw materials, which are linked to the transfer of land from food to energy crops, and also doubts as to whether biofuels are as environmentally friendly as originally thought, constitute a great obstacle for biodiesel production and commercialization (Dias et al., 2008). Likewise, EU Directive (2009/30/CE) establishes, with effect from 1 January 2017, that the greenhouse emission savings from the use of biofuels taken into account for the purpose of $10 \%$ shall be at least of $50 \%$ 
(being this value increased up to $60 \%$ from 1 January 2018). Annex IV of this Directive indicates that these greenhouse emission savings are in general lower than $50 \%$ for the production of biodiesel using conventional edible oils as feedstock, but in contrast, this value is increased over $80 \%$ using waste vegetable or animal oils. Therefore, it is of major importance studying alternative non-edible waste feedstocks for the sustainable production of biodiesel. Non-edible oils like those derived from jatropha, pongamia, jojoba, etc. are promising feedstocks especially in developing countries where edible oils are in short supply (Karmakar et al., 2010; Jain and Sharma, 2010). Likewise, waste cooking oil (WCO) is considered an economic and increasingly available resource for biodiesel production (Kee Lam et al., 2010; Han et al., 2009; Canakci, 2007). Although part of the produced WCO is collected for adequate disposal or treatment, most of the domestic WCO is usually discharged into the environment, being the origin of several problems in the waste water depuration systems. The valorisation of this used oil through the production of biodiesel would contribute to increase its recovery rate from the waste cycle. In addition, low-grade or waste animal fats can also be used as raw materials for the production of biodiesel (Canoira et al., 2008; Gürü et al., 2009; Lapuerta et al., 2009). Due to the enormous variety of possible animal fat sources, among the different waste fats whose use for the production of biodiesel has been reported, it is worth to mention waste chicken fat (Gürü et al., 2010), acid waste lard (Dias et al., 2009), beef tallow (Araujo et al., 2010), feather meal (Kondamudi et al., 2009), etc. In this sense, Mittelbach and Nebel (2006) reported three different classes of waste animal fats: category 1 , maximum-risk materials usually treated by incineration; category 2 , e.g. from dead stock or animals killed in disease control measures; and category 3 , slaughter wastes derived from healthy animals killed for human 
consumption. Other potential low-cost environmentally-friendly sources of biodiesel have been reported. For instance, the solvent extraction of waste coffee grounds yields $10-15 \%$ oil depending on the coffee species, which makes such a waste a potential candidate as raw material for biodiesel production. Besides, biodiesel derived from coffee grounds is highly stable (Kondamudi et al., 2008). Municipal sewage sludge (MSS) is also gaining attraction as a lipid feedstock for biodiesel production due to its significant concentration of lipids. MSS is plentiful all around the world and its management already poses formidable environmental problems. However, there are still numerous challenges faced by biodiesel production from waste sludge (Kargbo, 2010). Waste oils and fats generally contain relevant amounts of free fatty acids (FFA), water and unsaponifiable compounds such as hydrocarbons, carotenes, tocoferols, sterols, etc. (Lercker and Rodriguez-Estrada, 2000), which play a significant role in the transesterification reaction. The traditional homogeneous alkaline catalysts cannot be used to treat raw materials containing more than $0.5 \mathrm{wt} \%$ FFA, without compromising biodiesel yield, due to soap formation (Kee Lam et al., 2010; Leung et al., 2010; Vasudevan and Briggs, 2008). As a consequence, an acid-catalyzed conditioning step is usually required to reduce FFA content previously to the transesterification reaction (Marchetti et al., 2007). Furthermore, the use of homogeneous base catalysts makes impossible the catalyst recovery, generates neutralization wastewaters from the product streams and gives low-grade raw glycerol (Bournay et al., 2005). Using heterogeneous acid catalysts would help to overcome these drawbacks, making feasible the one-step efficient transformation of high FFA-containing feedstocks into biodiesel (Demirbas, 2007). However, the design of a highly active and selective heterogeneous acid catalyst is compulsory to achieve suitable results (Lotero et al., 2005). An ideal solid acid 
catalyst should join the following features: large pore size to minimize diffusion restrictions; high concentration of Brönsted acid sites; high catalytic stability against leaching and poisoning effects; and the possibility of tuning the surface hydrophobicity to promote the preferential adsorption of substrates and repulsion of highly polar compounds which could cause deactivation. A wide collection of heterogeneous acid catalysts has been tested for biodiesel production either by means of esterification and/or transesterification (Melero et al., 2009a). In this context, organosulfonic acidfunctionalized mesoporous silicas have revealed as interesting catalysts for the production of biodiesel. These materials are characterized by high surface area, large uniform pores, high thermal stability, accessible Brönsted acid sites, and the capability to control the surface hydrophilic/hydrophobic balance as well as the strength and concentration of acid sites (Melero et al., 2006). Recently, we have demonstrated that these catalysts show high catalytic performance in the synthesis of biodiesel from both refined and crude vegetable oils, giving high yields to FAME at temperatures and quite moderate methanol-to-oil molar ratios as compared with reported values for other acid solids (Melero et al., 2009b). Among the different sulfonic acid-based catalyst, arenesulfonic acid-functionalized SBA-15 provided the best combination of catalytic activity and reusability with crude palm oil (Melero et al., 2010a, 2010b). Therefore, the present work represents the continuation on this research with the aim to explore the catalytic behaviour of this material in the production of FAME from alternative lowcost feedstocks such as waste oils and fats. These low-grade raw materials have been thoroughly characterized in order to correlate the catalytic results with the composition thereof, as well as to evaluate possible purification pre-treatments to improve the activity and reusability of the catalyst. 


\section{Materials and Methods}

\subsection{Materials}

The low-grade animal fats used as biodiesel feedstocks in the present work were obtained as follows: Category-1 fat; lard and mixed fat -consisting of a mixture of lowgrade chicken, pig and beef fats sold for the preparation of animal feeds- were acquired from Ibergrasa S.A (Madrid, Spain); waste cooking oil (WCO) was obtained from the waste-management facility of Biogras S.L. (Madrid, Spain), treated by a simple filtration procedure to remove suspended solids. As reference for comparison purposes, crude and refined soybean oils supplied by Gustav-Heess (Barcelona, Spain), and crude palm oil supplied by Gran Velada (Zaragoza, Spain), were used.

Methanol (ACS grade), used as transesterifying agent, was supplied by Aldrich, and it was used as received. Pluronic $123\left(\mathrm{EO}_{20}-\mathrm{PO}_{70}-\mathrm{EO}_{20}\right)$ surfactant non-ionic polymer (Aldrich) was used as template for the self-assembling synthesis of the mesoporous SBA-15-type material. Tetraethyl orthosilicate (TEOS 98\%, Aldrich) and 2-(4-chlorosulfonyl phenyl)ethyltrimethoxy silane (CSPTMS, 50\% in methylene dichloride, ABCR) were used as silica and sulfonic acid precursors, respectively. Sulfonic acid resin Amberlyst-15 (Rohm \& Haas) was used for the cationic-exchange purification of the raw materials.

\subsection{Characterization of fats and oils}

Fats and oils used as raw materials for the production of biodiesel were characterized considering: (i) acid value by volumetric titration according to the standard UNE EN ISO 660:2000; (ii) density following the analytic method UNE EN 
ISO 3675:1999 with a Stanhope-Seta $12461 / 06 \mathrm{X}$ hydrometer at $40^{\circ} \mathrm{C}$ to ensure liquid phase of every sample; (iii) viscosity at $40^{\circ} \mathrm{C}$ according to method UNE EN ISO 3104:1996 (viscosimeter Cannon 200); (iv) metals content according to the standard ASTM D5185:09 by means of Inductively Coupled Plasma Atomic Emission Spectroscopy (ICP-AES); (v) fatty acid profile by gas chromatography (GC) according to the standard UNE EN ISO 5508:1996 and 5509/2000 using a Varian 3900 gas chromatograph equipped with a ZB-WAX column (30 m x $0.32 \mathrm{~mm}$ I.D., $0.25 \mu \mathrm{m}$ thickness. Phenomenex, Torrance, CA, USA) and a flame ionization detector (FID); (vi) water content by Karl Fischer coulometric titration according to the standard UNE EN ISO 12937:2001; and (vii) unsaponifiable matter -substances non-volatile at $100-105^{\circ} \mathrm{C}$ obtained by extraction with an organic solvent from the sample after saponificationfollowing the method described in literature [Plank and Lorbeer, 1994]. All titrations were performed in a potentiometric automatic titrator Metrohm Titrando 836.

\subsection{Synthesis of the sulfonic acid-modified mesoporous catalyst}

Arenesulfonic acid-functionalized mesoporous silica SBA-15 catalyst (Ar-SBA15) was prepared following a co-condensation method previously described in literature (Melero et al., 2002). Sulfonic acid functionalization was performed using CSPTMS as organosilane precursor. The degree of organic functionalization was fixed at $10 \%$ molar ratio based on total silicon atoms. In a typical synthesis, the Pluronic surfactant ( $4 \mathrm{~g}$, $0.69 \mathrm{mmol}$ ) was dissolved in $125 \mathrm{~mL}$ of $1.9 \mathrm{~N}$ hydrochloric acid at room temperature. The medium was then heated at $40^{\circ} \mathrm{C}$ and TEOS $(7.67 \mathrm{~g}, 36.9 \mathrm{mmol})$ was added under vigorous stirring. The resultant solution was then allowed to pre-hydrolyze for $45 \mathrm{~min}$ to facilitate the formation of an incipient silica mesostructure that allocates the sulfonic 
organic moieties in an optimal fashion. Afterwards, CSPTMS (2.67 g, $4.1 \mathrm{mmol})$ was added drop-wise and the resultant solution was stirred at $40^{\circ} \mathrm{C}$ for $20 \mathrm{~h}$ and then statically aged at $110^{\circ} \mathrm{C}$ for 24 additional hours. The resultant white solid was recovered by filtration and air-dried, previously to surfactant removal performed by double ethanol washing.

\subsection{Catalyst characterization}

Textural properties of the synthesized catalyst were obtained by means of nitrogen adsorption and desorption isotherms at $77 \mathrm{~K}$ using a Micromeritics TRISTAR 3000 system. The analysis of data was performed using the model of Barret-JoynerHalenda (BJH) (Barret et al., 1951) applying the correction by Kruk-Jaroniec-Sayari (KJS) (Kruk et al., 1997), and total pore volume was taken at $\mathrm{P} / \mathrm{Po}=0.985$. Low-angle X-ray powder diffraction (XRD) was employed for determining the structural ordering on a PHILIPS X'PERT apparatus using the $\mathrm{Cu} \mathrm{K} \alpha$ line radiation. Cationic-exchange capacity (acid capacity) was potentiometrically determined by titrating a suspension of catalyst in $2 \mathrm{M} \mathrm{NaCl}$ (aq.) with dropwise addition of $0.01 \mathrm{M} \mathrm{NaOH}$ (aq). Sulfur content was determined by means of elemental analysis in a Vario EL III apparatus. Thermogravimetric analysis in a SDT 2960 simultaneous DSC-TGA from TA Instruments $\left(5^{\circ} \mathrm{C} \cdot \mathrm{min}^{-1}\right.$ up to $700^{\circ} \mathrm{C}$ in air) was used as analytical technique for the quantification of organic loading. Table 1 summarizes the most relevant physicochemical properties for the arenesulfonic acid-modified mesostructured material. Data from XRD evidence high mesoscopic ordering in 2D-hexagonal pore arrangement, whereas the nitrogen adsorption-desorption isotherm confirms the presence of high surface area combined with narrow pore sizes distribution around $8 \mathrm{~nm}$ 
-size enough to minimize steric constraints when treating bulky substrates such as triglycerides. The average wall thickness is relatively high, lending good stability to the mesoporous structure. The synthesized material also displays a high incorporation yield of the sulfonic precursor, and almost complete accessibility to the sulfonic acid moieties.

\subsection{Catalytic experiments}

Catalytic tests were carried out in a $25 \mathrm{~mL}$ stainless-steel autoclave (Autoclave Engineers) equipped with temperature controller, mechanical stirrer and a pressure transducer to monitor inner pressure. In a typical experiment, oil or fat $(5 \mathrm{~g})$, methanol ( $5.66 \mathrm{~g}$, molar ratio methanol to oil of 30$)$ and catalyst ( $0.4 \mathrm{~g} ; 8 \mathrm{wt} \%$ based on oil/fat) were placed inside the reactor vessel, the system was hermetically closed and the temperature $\left(160^{\circ} \mathrm{C}\right)$ and stirring conditions $(2000 \mathrm{rpm})$ set up. These reaction conditions were selected taking into account our previous work on the transesterification of crude palm oil using similar catalysts (Melero et al., 2010a). The reaction was allowed to proceed for 2 hours and afterwards the reactor was cooled down using an ice-water bath. Collection of reaction products and catalyst was performed using acetone $(25 \mathrm{~mL})$ as solvent in order to ensure a complete recovery of all the reactants and products. The resultant solution was filtered using a nylon-membrane filter aiming to recover the catalyst minimizing solid losses (for catalyst reuse experiments). The acetone and the residual methanol were removed by means of rotary evaporation under vacuum. In the recycling tests, recovered catalysts were doublewashed with methanol and $n$-hexane for the removal of both polar and non-polar surface-adsorbed compounds (Jacobson et al., 2008), and dried overnight at $80^{\circ} \mathrm{C}$ 
previously to a second reaction use. The calculation of the yield of the transformation of fatty acid alkyl chains -comprising both FFA and glycerides- into fatty acid methyl esters $\left(\mathrm{Y}_{\mathrm{FAME}}\right)$ in the transesterification reactions was carried out on crude reaction samples without any further purification, i.e, without washing the produced biodiesel. For doing so, ${ }^{1} \mathrm{H}$ NMR analyses were performed in a Varian Mercury Plus 400 unit in a similar way to that described by Gelbard et al. (1995). It must be noted that this approach represents the molar yield towards FAME relative to total fatty acid chains, and hence does not take into account for the calculus the non-fatty fraction of the starting raw material, i.e. the unsaponifiable fraction.

\section{Results and discussion}

\subsection{Properties of the low-grade oil and fats}

The first aim of the present work was to assess the properties of the raw materials which could exert a more relevant effect on the catalytic behaviour of a solid acid catalyst such as the sulfonic acid-SBA-15 material used for the production of FAME in this work. Thus, Table 2 includes properties such as acid value, density and viscosity at $40^{\circ} \mathrm{C}$, metals content, water and unsaponifiable matter as well as the fatty acid profile for each oil or fat. In general, the level of FFA content, as determined by acid value, is considered the most limiting property for the production of biodiesel through the conventional homogeneous base-catalyzed route. An acid value over 1 $\mathrm{mg}_{\mathrm{KOH}} / \mathrm{g}$ (equivalent to FFA $0.5 \mathrm{wt} \%$ ) would not be adequate for a base-catalyzed process. Analyzing the results shown in Table 2, WCO, Category-1 fat, mixed fat, crude palm oil and crude soybean oil display acid values well over $1 \mathrm{mg}_{\mathrm{KOH}} / \mathrm{g}$, being the FFA contents of Category-1 fat and crude palm oil especially noteworthy. It must also be 
noted that, unexpectedly, low-grade lard provided a very low acidity, close to the level of a refined feedstock such as the refined soybean oil.

The maximum contents of certain elements such as phosphorous or light metals (alkaline and alkaline earth metals) are regulated by international biodiesel standards (EN 14214 and ASTM D6751) and their presence in the feedstocks may also affect the acid-catalyzed conversion into biodiesel. Control of $\mathrm{P}$ content is crucial, not only because its occurrence in biodiesel can be harmful to diesel engines and usually a degumming process is performed for its reduction, but also because it can produce the deactivation of the acidic catalytic sites by deposition of oligomeric units and subsequent pore blockage. On the other hand, light metals such as sodium, potassium, magnesium or calcium, can produce the cationic-exchange of the catalytic protons in the sulfonic acid sites, thus leading to the deactivation of the catalyst. Table 2 compiles the metal contents determined by ICP-AES for each oil and fat. As expected, crude materials contain significant amounts of both phosphorous and light metals. P content was especially high for the mixed fat and the crude soybean oil, while metals content were also high in Category- 1 fat and mixed fat. In contrast, the WCO used in this study did not show significant amounts of metal and phosphorous impurities.

Water and unsaponifiable matter contents were also deemed relevant properties from a catalytic point of view. Acid-catalyzed processes are typically affected by the presence of water in the reaction media, as the hydrophilic nature of the acid active sites tends to produce water-rich microenvironments around them (Morales et al., 2008). This would result in an equilibrium shift of the esterification/hydrolysis reactions in the vicinity of the catalytic sites, which ultimately would reduce the formation of FAME. As shown in Table 2, the low-cost oil and fats generally have relatively high water 
contents as compared with the refined oil. Indeed, Category-1 fat, WCO and mixed fats have water content close to or over 1000 ppm. Likewise, unsaponifiable matter -defined as the whole quantity of substances present in the oil or fat which, after saponification by potassium hydroxide and extraction by a specific solvent, are not soluble in aqueous alkali and non-volatile under the condition of test- represents a non-convertible fraction whose effect on the catalytic performance needs to be elucidated. The values recorded for this parameter are particularly noteworthy in Category-1 and mixed fats, 22.6 and $9.8 \mathrm{wt} \%$, respectively. Low-grade lard and $\mathrm{WCO}$ presented unsaponifiable matter contents similar to that detected for the refined soybean oil. Used cooking oil comes from fully refined vegetable oils, e.g. olive oil and sunflower oil in Spain, that upon warming during cooking undergo degradation process due to oxidation reactions. Such reactions, in a common use, should not substantially increase the amount of unsaponifiable matter.

Table 2 also incorporates the density and viscosity at $40^{\circ} \mathrm{C}$ and fatty acid profile of the different feedstocks. All the results are consistent with reported values for these kinds of materials. The assessment of the fatty acid profiles revealed the more saturated nature of the animal fats, showing high total contents in myristic, palmitic and stearic acids: $42.2,45.4$, and $51.2 \mathrm{wt} \%$ for low-grade lard, mixed fat and category-1 fat, respectively. Furthermore, the proportion of poly-unsaturated fatty acids in these raw materials is very low as compared to the vegetable raw materials, which is a rather good situation for obtaining highly stable biodiesel, though cold flow properties might be compromised.

\subsection{Catalytic tests}


The catalytic activity of arenesulfonic acid-functionalized SBA-15 silica -herein denoted as Ar-SBA-15- in the transformation of low-grade oils and fats into FAME was assessed using previously optimized reaction conditions: $160^{\circ} \mathrm{C} ; 30$ methanol to oil molar ratio; 8 wt\% catalyst loading; 2000 rpm stirring rate. Under these optimal conditions, determined by means of response surface methodology, Ar-SBA-15 catalyst provided over $80 \%$ molar yield to FAME after $2 \mathrm{~h}$ using crude palm oil (Melero et al., 2010a).

Fig. 1 shows the yield to FAME achieved for the different lipidic raw materials in two sets of experiments: using fresh catalyst and reusing the catalyst in a second consecutive run with intermediate catalyst washing. As shown, the first use of the catalyst Ar-SBA-15 provided very good results for every used raw material leading to FAME yields close to $80 \%$ after $2 \mathrm{~h}$. This is a clear indication of the high activity of arenesulfonic acid sites in both the esterification and transesterification reactions, independently of the starting raw material. Therefore, the above-discussed different properties and compositions of the raw materials apparently do not have an impact on the catalytic activity during the first use of the catalyst. It must also be noted that the obtained yields would be expected to increase with longer reaction times; or introducing modifications within the catalyst, such as increasing the surface hydrophobicity by endcapping surface silanol groups (Melero et al., 2010b). The aim of the present study, nevertheless, was to discuss differences among the low-grade starting materials and not to maximize the yield to FAME.

With regards to the reutilization experiments, the vegetable oils -crude palm and soybean oils and refined soybean oil- as well as WCO and low-grade lard, were transformed in a similar quantity as in the first cycle, reproducing the initial values of 


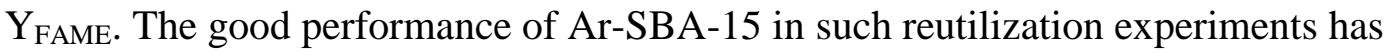
already been reported for crude palm oil (Melero et al., 2010b), and now this trend is also confirmed for other vegetable oils and, more importantly, for low-grade materials such as low-grade lard and waste cooking oil. However, for mixed fat and category-1 fat the reusing experiments evidenced a drastic loss of catalytic activity. The stronger effect was observed for category-1 fat, where $\mathrm{Y}_{\text {FAME }}$ dramatically dropped to $25 \%$ (initial $\mathrm{Y}_{\mathrm{FAME}}$ about $80 \%$ ). Also, mixed fat provided a significant reduction, from $84 \%$ down to $49 \%$. These results indicate that the catalyst has undergone a deactivating process during its first use when utilizing these particular raw materials. Additionally, such a deactivation is not overcome after double-washing the catalyst -with methanol and $n$ hexane. In order to determine the actual causes of deactivation, we have performed a graphical correlation (Fig. 2) between the activity loss in the reuse of the catalyst and selected relevant properties of the raw materials: water content; unsaponifiable matter; alkaline and alkaline earth metals content; and phosphorous content. Loss of activity has been calculated as the difference in $\mathrm{Y}_{\mathrm{FAME}}$ in the two consecutive uses of the catalyst Ar-SBA-15 for each feedstock, and denoted as $\Delta \mathrm{Y}_{\mathrm{FAME}}$. In general terms, $\Delta \mathrm{Y}_{\mathrm{FAME}}$ values increase with the different properties, confirming that they can be the cause of the detrimental impact on the activity of Ar-SBA-15 catalyst. Although this analysis does not allow discriminating the individual effects and it is not obvious which property displays the predominant effect, category-1 fat and mixed fat which, unlike the other feedstocks, simultaneously combine high values of the four properties and provided the highest catalyst deactivation results (highest $\Delta \mathrm{Y}_{\mathrm{FAME}}$ values). Therefore, a direct correlation with the loss of catalytic activity can be established. Making an individual analysis, WCO did not undergo any loss of activity despite its high water content (1398 
ppm, Table 2), meaning that water content -at this level- is not a main deactivating cause. Also, crude soybean oil has a significant phosphorous content P (138 ppm, Table 2) that apparently did not impair the catalytic activity during the second use of the catalyst. This can also be translated into a low effect of $\mathrm{P}$ content on the deactivation of the sulfonic acid catalyst. On the other hand, feedstocks having a remarkable content of metals (over $100 \mathrm{ppm}$ ) or unsaponifiable matter (over $4 \mathrm{wt} \%$ ) are the most affected by the deactivation of the catalyst after a first reaction cycle, that is, category-1 fat and mixed fat. Therefore, it could be inferred that precisely these two properties are the most affecting ones.

\subsection{Effect of conditioning pre-treatment on the catalytic activity}

In order to reduce the above-discussed deactivating effect on arenesulfonic acidfunctionalized SBA-15 catalyst when applied to category-1 and mixed fats, the following study was carried out. Several conditioning pre-treatments were considered for the purification of the raw materials with the objective of reducing the levels of the two properties identified as feasible deactivating causes: alkaline and alkaline earth metals and unsaponifiable matter contents. The pre-treatments also aim to reduce water and phosphorous contents. Such pre-treatments basically consisted of washing the feedstock in aqueous media at $40^{\circ} \mathrm{C}$ for $1 \mathrm{~h}$ in the presence of the sulfonic acid commercial resin Amberlyst-15 as cationic-exchange agent $\left(40 \mathrm{~g}\right.$ fat, $10 \mathrm{~mL} \mathrm{H} \mathrm{H}_{2} \mathrm{O}$, and 1 g resin), and/or overnight drying at $100^{\circ} \mathrm{C}$. Aqueous washing is part of a typical degumming process to reduce $\mathrm{P}$ content, and the use of Amberlyst-15 is indicated for the removal of metal cations. Depending on the polarity of the compounds, a fraction of the unsaponifiable matter may also be removed from the raw material with this 
purification treatment. Thus, Table 3 includes the properties of category- 1 fat and mixed fat after the conditioning pre-treatment. As shown, the aqueous washing in the presence of the cationic-exchange resin successfully removed most of the alkaline and alkaline earth metal cations, leading to very low final contents. Phosphorous was also significantly removed in both cases, though not completely, still remaining at a concentration of about $40 \mathrm{ppm}$. Likewise, the characterization revealed a significant reduction in the fraction of unsaponifiable matter, most likely coming from the removal of water-soluble polar compounds. In spite of water content increased as a consequence of the aqueous treatment, the subsequent application of a drying step at $100^{\circ} \mathrm{C}$ finally reduced humidity values below 200 ppm for both fats. It must also be noted that as a side-effect, acid values increased with the conditioning pre-treatment, especially for category-1 fat. This is attributed to hydrolysis of glycerides to FFAs promoted during the aqueous treatment at $40^{\circ} \mathrm{C}$ in the presence of an acid resin.

The use of the conditioned animal fats in the acid-catalyzed production of FAME is summarized in Fig. 3. For each treatment, the figure depicts the $Y_{\text {FAME }}$ corresponding to the first and second uses of the catalyst in order to evaluate the impact of the pre-conditioning treatment on the deactivation of the Ar-SBA-15 catalyst. Firstly, it must be pointed out that no significant effect is observed on the catalytic performance using fresh catalyst, independently of the pre-treatment. As expected, this indicates that the increased FFA content of the conditioned raw materials does not impair the catalytic behavior of Ar-SBA-15 catalyst. However, important variations are observed in the catalyst reutilization experiments (second use). Treatment by simple drying ( $\mathrm{B}$ in the figures) slightly improves the catalytic activity in the second use. This indicates that the presence of water molecules actually has a contribution in the lowering of the activity of 
sulfonic acid-based catalyst, although it must be regarded as small. On the other hand, purification by washing/cationic-exchanging/drying ( $\mathrm{C}$ in the figures) produces a significant improvement of the catalytic activity. For mixed fat, this improvement results in the almost complete recovery of the starting catalytic activity, while for category-1 fat the resultant $Y_{\text {FAME }}$ was approximately $60 \%$, still far from the initial $80 \%$. Analyzing the properties of the conditioned raw materials (Table 3), the reduction of the content of metals and unsaponifiable matter is considered the main responsible for this beneficial effect. The complete recovery of the activity with the conditioned mixed fat is directly attributed to the reduction of these properties. However, for category-1 fat, the purification still yielded a content of unsaponifiable matter of $11.1 \mathrm{wt} \%$, similar to the content displayed by the as-received mixed fat. An additional treatment consisting of a double washing/exchanging followed by a drying step (D in Fig. 3) was performed on category-1 fat in order to further reduce the unsaponifiable matter content. Unfortunately, the resultant purified fat still showed an unsaponifiable matter content close to $10 \mathrm{wt} \%$, indicating that the second washing and ionic-exchanging step has a very low efficiency for the removal of this remaining fraction of unsaponifiable compounds. As a result, the catalytic results are very similar to those obtained after a single washing/exchanging (treatment $\mathrm{C}$ ).

After these results, we think that the most influential parameter on the deactivating effect is precisely the unsaponifiable matter content, especially considering that both the catalytic behavior and the content of unsaponifiable matter of conditioned category-1 fat (treatment C) and dried mixed fat (treatment B) are quite similar. This is also in agreement with the trends above discussed for Fig. 2. Apparently, the deactivating mechanism might be the strong interaction of relatively polar 
unsaponifiable compounds with the catalytic sulfonic acid sites. As a consequence of this interaction, the methanol and $n$-hexane double-washing of the catalyst between consecutive uses is not able to remove such compounds. In order to verify this hypothesis, we have performed a series of thermogravimetric analyses to get further information about the composition of the used Ar-SBA-15 catalysts. In these analyses, the weight losses corresponding to Ar-SBA-15 as recovered from reaction medium after being used in a reaction cycle with both types of fat have been obtained. Since the catalyst has not yet been washed at this stage, there is a large amount of organic matter within the pore structure. In this way, two pronounced weight losses are observed in both cases (see supporting information), at about $200^{\circ} \mathrm{C}$, which can be easily attributed to FAME molecules, and about $300^{\circ} \mathrm{C}$, attributed to unreacted triglycerides. At higher temperatures (over $400^{\circ} \mathrm{C}$ ), the observed weight loss is due to the thermal decomposition of the arenesulfonic moieties (Melero et al., 2002).

To confirm the strong adsorption of organic unsaponifiable compounds on the catalytic sites, additional thermogravimetric analyses were run on washed Ar-SBA-15 catalysts, confirming that most of the adsorbed organic matter is removed from the catalyst with the double washing procedure with methanol and $n$-hexane. However, the TG profile of the washed catalysts was still slightly different from that of the fresh catalyst and its analysis revealed an increase of the organic loading in the zone of the sulfonic moieties. Table 4 summarizes, for the different Ar-SBA-15 catalysts analyzed in this study, the calculated organic loadings referred to residual $\mathrm{SiO}_{2}$ content ( $\left.\mathrm{g}_{\text {org }} / \mathrm{g}_{\mathrm{SiO} 2}\right)$ from the weight loss in the range of $200-700^{\circ} \mathrm{C}$, where no interference of volatile compounds, water or surfactant, is produced. As shown, after reaction with conditioned (treatment C) category-1 fat and double washing, Ar-SBA-15 catalyst 
suffers an increase of organic loading from 0.297 to $0.502 \mathrm{~g} / \mathrm{g}_{\mathrm{SiO} 2}$. The difference must be attributed to the strong adsorption of organic compounds on the catalytic sulfonic sites, as the desorption temperature is coincident with the temperature of decomposition of the arenesulfonic acid sites. This correlates fairly with the above discussed reaction results and the impossibility of recovering the initial catalytic activity in a second run when treating category 1 fat. In contrast, for conditioned mixed fat, the catalyst used shows an organic content in the range $200-700^{\circ} \mathrm{C}$ that is quite similar to that of the fresh catalyst $\left(0.285 \mathrm{~g} / \mathrm{g}_{\mathrm{SiO} 2}\right)$. This is consistent with the almost complete recovery of the catalytic activity for a second reaction cycle (Fig. 3, mixed fat, treatment C). The lower unsaponifiable matter content of conditioned mixed fat versus conditioned category-1 fat is the main explanation for this behavior. This provides further evidence indicating that the presence of a significant amount of unsaponifiable matter has a deactivation effect on the sulfonic acid-based catalyst due to strong adsorption phenomena.

\section{Conclusions}

Low-grade oils and fats contains a number of impurities such as unsaponifiable matter, water, phosphorous and metals, having a negative effect on the yield of FAME, compromising the reutilization of arenesulfonic acid-functionalized SBA-15 catalyst. The main catalyst deactivation cause was the strong interaction of unsaponifiable matter with the acid sites. A previous feedstock conditioning consisting on an aqueous washing, in presence of a cationic-exchange resin, followed by a drying steps remarkably increased the FAME yield in a second use of the catalyst. 


\section{Acknowledgements}

The financial support from the "Ministerio de Ciencia e Innovación" through the project CTQ2008-01396 and from the Regional Government of Madrid through the project S2009-ENE1743 is gratefully acknowledged. RSV would like to thank the Spanish Ministry of Science and Innovation for a FPU predoctoral grant. 


\section{References}

Araujo B.Q., da Rocha Nunes R.C., de Moura C.V.R., de Moura E.M., das Graças Lopes Citó A.M., dos Santos Junior J.R., 2010. Synthesis and Characterization of Beef Tallow Biodiesel. Energy Fuels, 24, 4476-4480.

Barret E.P., Joyner L.G., Halenda P.B., 1951. The Determination of Pore Volume and Area Distributions in Porous Substances. J. Am. Chem. Soc., 73, 373-380.

Bournay L., Casanave D., Delfort B., Hillion G., Chodorge J.A., 2005. New heterogeneous process for biodiesel production: A way to improve the quality and the value of crude glycerin produced by biodiesel plants. Catal. Today, 106, 190-192.

Canakci M., 2007, The potential of restaurant waste lipids as biodiesel feedstocks. Bioresour. Technol., 98, 183-190.

Canoira L., Rodríguez-Gamero M., Querol E., Alcántara R., Lapuerta M., Oliva F., 2008, Biodiesel from low-grade animal fat: production process assessment and biodiesel properties characterization. Ind. Eng. Chem. Res., 47, 7997-8004.

Demirbas A., 2007. Comparison of transesterification methods for production of biodiesel from vegetable oils and fats. Energ. Convers. Manage., 49, 125-130.

Dias J.M., Alvim-Ferraz M.C.M., Almeida M.F., 2008. Mixtures of vegetable oils and animal fat for biodiesel production: Influence on product composition and quality. Energy Fuels, 22. 3889-3893.

Dias J.M., Alvim-Ferraz M.C.M., Almeida M.F., 2009. Production of biodiesel from acid waste lard. Bioresour. Technol., 100, 6355-6361.

Freedman B., Pryde E.H., Mounts T.L., 1984, Variables affecting the yield on fatty esters from transterified vegetable oils. J. Am. Oil Chem. Soc., 61, 1638-43. 
Gelbard G., Bres O., Vargas R.M., Vielfaure F., Schuchardt U.F., 1995. 1H nuclear magnetic resonance determination of the yield of the transesterification of rapeseed oil with methanol. J. Am. Oil Chem. Soc., 72, 1239-1241.

Gürü M., Artukoglu B.D., Keskin A., Koca A., 2009. Biodiesel production from waste animal fat and improvement of its characteristics by synthesized nickel and magnesium additive. Energ. Convers. Manage., 50, 498-502.

Gürü M., Koca A., Can Ö., Çinar C., Sahin F., 2010. Biodiesel production from waste chicken fat based sources and evaluation with $\mathrm{Mg}$ based additive in a diesel engine. Renew. Energ., 35, 637-643.

Han M., Yi W., Wu Q., Liu Y., Hong Y., Wang D., 2009. Preparation of biodiesel from waste oils catalyzed by a Bronsted acidic ionic liquid. Bioresour. Technol., 100, 2308-2310.

Jacobson K, Gopinath R, Meher LC, Dalai AK, 2008. Solid acid catalyzed biodiesel production from waste cooking oil. Appl Catal. B, 85, 86-91.

Jain S., Sharma M.P., 2010. Biodiesel production from Jatropha curcas oil. Renew. Sust. Energ. Rev., 14, 3140-3157.

Kargbo D.M., 2010. Biodiesel Production from Municipal Sewage Sludges. Energy Fuels, 24, 2791-2794.

Karmakar A., Karmakar S., Mujherjee S., 2010. Properties of various plants and animals feedstocks for biodiesel production. Bioresour. Technol., 101, 7201-7210.

Kee Lam M., Teong Lee K., Rahman Mohamed A., 2010. Homogeneous, heterogeneous and enzymatic catalysis for transesterification of high free fatty acid oil (waste cooking oil) to biodiesel: a review. Biotechnol. Adv., 28, 500-518. 
Kondamudi N., Mohapatra S.N., Misra M., 2008. Spent coffee grounds as a versatile source of green energy. J. Agr. Food. Chem., 56, 11757-11760.

Kondamudi N., Strull J., Misra M., Mohapatra S.K., 2009. A Green Process for Producing Biodiesel from Feather Meal. J. Agric. Food Chem., 57, 6163-6166.

Kruk M., Jaroniec M., Sayari A., 1997. Application of Large Pore MCM-41 Molecular Sieves To Improve Pore Size Analysis Using Nitrogen Adsorption Measurements. Langmuir, 13, 6267-6273.

Lapuerta M., Rodríguez-Fernández J., Oliva F., Canoira L., 2009. Biodiesel from Low-Grade Animal Fats: Diesel Engine Performance and Emissions. Energy Fuels, 23, 121-129.

Lercker G. and Rodriguez-Estrada M.T., 2000. Chromatographic analysis of unsaponifiable compounds of olive oils and fat-containing foods. J. Chromatogr. A, 881 (1-2), 105-129.

Leung D. Y.C., Wu X., Leung M.K.H., 2010. A review on biodiesel production using catalyzed transesterification. Appl. Energ., 87, 1083-1095.

Lotero E., Liu Y., Lopez D.E., Suwannakarn K., Bruce D.A., Goodwin Jr. J.G., 2005. Synthesis of biodiesel via acid catalysis. Ind. Eng. Chem. Res., 44, 5353-5363.

Marchetti J.M., Miguel V.U., Errazu A.F., 2007. Possible methods for biodiesel production. Renew. Sust. Energ. Rev., 11, 1300-1311.

Melero J.A., Stucky G.D., van Grieken R., Morales G., 2002. Direct syntheses of ordered SBA-15 mesoporous materials containing sulfonic acid groups. J. Mater. Chem., 12, 1664-1670. 
Melero J.A, van Grieken R., Morales G., 2006. Advances in the Synthesis and Catalytic Applications of Organosulfonic-Functionalized Mesostructured Materials. Chem. Rev., 106, 3790-3812.

Melero J.A., Iglesias J., Morales G., 2009a. Heterogeneous acid catalysts for biodiesel production: current status and future challenges. Green Chem., 11, 1285-1308.

Melero J.A., Bautista L.F., Morales G., Iglesias J., Briones D., 2009 b. Biodiesel production with heterogeneous sulfonic acid-functionalized mesostructured catalysts. Energy Fuels, 23. 539-547.

Melero J.A., Bautista L.F., Iglesias J., Morales G., Sánchez-Vázquez R., Suárez I., 2010a. Biodiesel production over arenesulfonic acid-modified mesostructured catalysts: optimization of reaction parameters using response surface methodology. Top. Catal., 53, 795-804.

Melero J.A., Bautista L.F., Morales G., Iglesias J., Sánchez-Vázquez R., 2010b. Biodiesel production from crude palm oil using sulfonic acid-modified mesostructured catalysts. Chem. Eng. J., 161, 323-331.

Mittelbach M., Nebel B.A., 2006. Biodiesel from extracted fat out of meat and bone meal. Eur. J. Lipid Sci. Technol., 108, 398-403.

Morales G., Athens G., Chmelka B.F., van Grieken R., Melero J.A., 2008. Aqueous-sensitive reaction sites in sulfonic acid-functionalized mesoporous silicas. J. Catal., 254, 205-217.

Plank C. and Lorbeer E., 1994. Minor components in vegetable oil methyl esters I: sterols in rape seed oil methyl ester. Fat Sci. Technol., 96, 10, 379-386.

Vasudevan P.T., Briggs M., 2008. Biodiesel production - current state of the art and challenges. J. Ind. Microbiol. Biotechnol., 35, 421-430 
Table 1. Physicochemical properties of the arenesulfonic acid-modified mesostructured SBA-15 silica.

\begin{tabular}{|c|c|c|c|c|c|c|c|c|}
\hline \multirow{3}{*}{ Sample } & \multicolumn{5}{|c|}{ Textural Properties } & \multicolumn{3}{|c|}{ Acid Properties } \\
\hline & \multirow{2}{*}{$\begin{array}{l}d_{100}{ }^{\mathrm{a}} \\
(\AA)\end{array}$} & \multirow{2}{*}{$\begin{array}{l}\text { Pore size }{ }^{b} \\
(\AA)\end{array}$} & \multirow{2}{*}{$\begin{array}{l}\text { BET area } \\
\left(\mathrm{m}^{2} / \mathrm{g}\right)\end{array}$} & \multirow{2}{*}{$\begin{array}{l}\text { Pore volume } \\
\qquad\left(\mathrm{cm}^{3} / \mathrm{g}\right)\end{array}$} & \multirow{2}{*}{$\begin{array}{l}\text { Wall thick. }{ }^{\mathrm{d}} \\
(\AA)\end{array}$} & \multicolumn{2}{|c|}{$\begin{array}{c}\text { Acid capacity } \\
\text { (meq/g) }\end{array}$} & \multirow{2}{*}{$\begin{array}{c}\text { Accessibility }^{\mathrm{f}} \\
(\%)\end{array}$} \\
\hline & & & & & & Sulfur & $\mathrm{H}^{+}$ & \\
\hline Ar-SBA-15 & 106 & 83 & 706 & 0.89 & 39 & 1.07 & 1.03 & 96 \\
\hline
\end{tabular}

${ }^{\mathrm{a}} d(100)$ spacing, measured from small-angle X-ray diffraction.

${ }^{\mathrm{b}}$ Mean pore size $\left(\mathrm{D}_{\mathrm{p}}\right)$ from adsorption branch applying the BJH model.

${ }^{\mathrm{c}}$ The total pore volume $\left(\mathrm{V}_{\mathrm{p}}\right)$ was taken at $\mathrm{P} / \mathrm{P}_{\mathrm{o}}=0.975$ single point.

${ }^{\mathrm{d}}$ Average pore wall thickness calculated by $a_{o}$-pore size $\left(a_{o}=2 d(100) / \sqrt{ } 3\right)$.

${ }^{\mathrm{e}}$ Acid capacity defined as meq of acid centers per $\mathrm{g}$ of catalyst (obtained either directly by titration or indirectly from sulfur content by elemental analysis).

${ }^{\mathrm{f}}$ Defined as the ratio between $\mathrm{H}^{+}$from acid-base titration and sulfur content from elemental analysis. 
Table 2. Properties of low-grade oil and fats evaluated as biodiesel feedstocks.

\begin{tabular}{|c|c|c|c|c|c|c|c|c|c|}
\hline \multirow[b]{2}{*}{ Property } & \multirow[b]{2}{*}{ Analytical Method } & \multirow[b]{2}{*}{ Unit } & \multicolumn{7}{|c|}{ Value } \\
\hline & & & $\begin{array}{c}\text { Low-grade } \\
\text { lard }\end{array}$ & $\begin{array}{c}\text { Category } 1 \\
\text { fat }\end{array}$ & $\begin{array}{c}\text { Mixed } \\
\text { fat }\end{array}$ & $\begin{array}{c}\text { Waste cooking } \\
\text { oil }\end{array}$ & $\begin{array}{c}\text { Crude Palm } \\
\text { Oil }\end{array}$ & $\begin{array}{c}\text { Crude Soybean } \\
\text { Oil }\end{array}$ & $\begin{array}{c}\text { Refined } \\
\text { Soybean Oil }\end{array}$ \\
\hline Acid value & UNE EN ISO 660:2000 & $\mathrm{mg}_{\mathrm{KOH}} / \mathrm{g}$ & 0.47 & 33.45 & 3.57 & 4.06 & 21.45 & 2.20 & 0.07 \\
\hline Density at $40^{\circ} \mathrm{C}$ & UNE EN ISO 3675:1999 & $\mathrm{kg} / \mathrm{m}^{3}$ & 894 & 829 & 920 & 918 & 908 & 910 & 905 \\
\hline Viscosity at $40^{\circ} \mathrm{C}$ & UNE EN ISO 3104:1996 & $\mathrm{mm}^{2} / \mathrm{s}$ & 48.7 & 47.4 & 52 & 66.5 & 42.9 & 38.2 & 36.8 \\
\hline \multirow[t]{6}{*}{ Metals content } & ASTM D5185-05 & ppm & & & & & & & \\
\hline & $P$ & & 72.6 & 85.9 & 302.8 & 3.1 & 13.1 & 138 & n.d. \\
\hline & $\mathrm{Na}$ & & n.d. & 154.4 & 83.8 & 2.8 & 15.7 & n.d. & n.d. \\
\hline & $\mathrm{K}$ & & 0.4 & 144.2 & 10.8 & n.d. & n.d. & 23.4 & n.d. \\
\hline & $\mathrm{Mg}$ & & 0.4 & 0.1 & 10.8 & n.d. & 4.9 & 23.5 & n.d. \\
\hline & $\mathrm{Ca}$ & & 4.5 & 2.6 & 123.3 & 0.5 & 5.3 & 39.5 & n.d. \\
\hline \multirow[t]{8}{*}{ Fatty acid profile } & UNE EN ISO 5508:1996 and 5509:2000 & $\mathrm{wt} \%$ & & & & & & & \\
\hline & Myristic acid (14:0) & & 1.4 & 3.1 & 2.1 & 0.2 & 0.8 & 0.0 & 0.1 \\
\hline & Palmitic acid (16:0) & & 26.6 & 28.1 & 26.6 & 9.3 & 43.3 & 10.7 & 11.6 \\
\hline & Palmitoleic acid (16:1) & & 3.0 & 0.0 & 3.4 & 0.5 & 0.0 & 0.0 & 0.0 \\
\hline & Stearic acid (18:0) & & 14.2 & 20.0 & 16.7 & 3.9 & 5.2 & 4.0 & 3.3 \\
\hline & Oleic acid (18:1) & & 47.0 & 41.6 & 42.1 & 54.5 & 39.7 & 28.2 & 25.7 \\
\hline & Linoleic acid (18:2) & & 6.2 & 6.0 & 7.6 & 29.7 & 10.5 & 48.7 & 53.9 \\
\hline & Linolenic acid (18:3) & & 0.4 & 0.5 & 0.57 & 0.3 & 0.4 & 7.4 & 4.6 \\
\hline Water content & UNE EN ISO 12937:2001 & ppm & 288 & 1170 & 956 & 1398 & 687 & 407 & 166 \\
\hline Unsaponifiable matter & Plank and Lorbeer, 1994 & $\mathrm{wt} \%$ & 2.9 & 22.6 & 9.8 & 1.0 & 2.5 & 2.9 & 1.2 \\
\hline
\end{tabular}

n.d.: not detected (below detection limit). 
Table 3. Properties of low-grade fats and waste cooking oil evaluated as biodiesel feedstocks after conditioning pre-treatment.

\begin{tabular}{|c|c|c|c|c|c|c|}
\hline \multirow{2}{*}{ Property } & \multirow{2}{*}{ Analytical Method } & \multirow{2}{*}{ Unit } & \multicolumn{2}{|c|}{ Category 1 fat } & \multicolumn{2}{|c|}{ Mixed fat } \\
\hline & & & As received & Conditioned $^{\text {a }}$ & As received & Conditioned $^{\mathrm{a}}$ \\
\hline Acid value & UNE EN ISO 660:2000 & $\mathrm{mg}_{\mathrm{KOH}} / \mathrm{g}$ & 33.45 & 41.80 & 3.57 & 5.99 \\
\hline \multirow{6}{*}{ Metals content } & ASTM D5185-05 & ppm & & & & \\
\hline & $\mathrm{P}$ & & 85.9 & 44.7 & 302.8 & 44.3 \\
\hline & $\mathrm{Na}$ & & 154.4 & 12.7 & 83.8 & 1.4 \\
\hline & $\mathrm{K}$ & & 144.2 & 8.4 & 10.8 & 2.9 \\
\hline & $\mathrm{Mg}$ & & 0.1 & 0.3 & 10.8 & 1.5 \\
\hline & $\mathrm{Ca}$ & & 2.6 & 1.8 & 123.3 & 2.5 \\
\hline Water content & UNE EN ISO 12937:2001 & $\mathrm{ppm}$ & 1170 & $2857 / 197^{b}$ & 956 & $1339 / 160^{\mathrm{b}}$ \\
\hline Unsaponifiable matter & Plank and Lorbeer, 1994 & wt\% & 22.6 & 11.1 & 9.8 & 4.0 \\
\hline
\end{tabular}

${ }^{a}$ Conditioning pre-treatment consisting of washing and cationic-exchanging in aqueous media with Amberlyst- 15 at $40^{\circ} \mathrm{C}$, followed

by drying at $100^{\circ} \mathrm{C}$ for $24 \mathrm{~h} .{ }^{b}$ Water content before/after drying. 
Table 4. Compositions of the arenesulfonic acid-modified mesostructured SBA-15 silica applied to the production of FAME from category-1 and mixed fats as determined by TG analysis.

\begin{tabular}{|c|c|c|c|}
\hline Ar-SBA-15 catalyst treatment & $\begin{array}{l}\text { Residual } \mathrm{SiO}_{2}{ }^{\mathrm{a}} \\
\quad(\mathrm{wt} \%)\end{array}$ & $\begin{array}{l}\text { Organic }^{b} \\
(\mathrm{wt} \%)\end{array}$ & $\mathrm{g}_{\mathrm{org}} / \mathrm{g}_{\mathrm{SiO} 2}$ \\
\hline Fresh & 72.7 & 21.6 & 0.297 \\
\hline $\begin{array}{l}\text { As recovered from reaction medium (with as-received } \\
\text { category-1 fat) }\end{array}$ & 27.5 & 73.6 & 2.676 \\
\hline $\begin{array}{l}\text { Double-washed with } \mathrm{MeOH} \text { and } \mathrm{n}-\mathrm{C}_{6} \text { after reaction with } \\
\text { conditioned category-1 fat (treatment } \mathrm{C} \text { ) }\end{array}$ & 64.5 & 32.4 & 0.502 \\
\hline $\begin{array}{l}\text { As recovered from reaction medium (with as-received mixed } \\
\text { fat) }\end{array}$ & 41.2 & 59.5 & 1.445 \\
\hline $\begin{array}{l}\text { Double-washed with } \mathrm{MeOH} \text { and } \mathrm{n}-\mathrm{C}_{6} \text { after reaction with } \\
\text { conditioned mixed fat (treatment } \mathrm{C} \text { ) }\end{array}$ & 76.2 & 21.7 & 0.285 \\
\hline
\end{tabular}

\footnotetext{
${ }^{\text {a }}$ Determined as the residual $\mathrm{wt} \%$ at $700^{\circ} \mathrm{C}$ from TGA.

${ }^{\mathrm{b}}$ Determined by TGA weight loss in the range of $100-700^{\circ} \mathrm{C}$ for as recovered catalysts and $200-700^{\circ} \mathrm{C}$ for fresh catalyst and recovered catalyst after double washing.
} 


\section{Figure captions}

Fig. 1. Yield to FAME from different fatty raw materials using Ar-SBA-15 in two consecutive runs with intermediate catalyst washing. Reaction conditions: $160^{\circ} \mathrm{C}$; methanol:oil molar ratio $=30$; catalyst loading $8 \mathrm{wt} \%$; time 2 hours; stirring rate 2000 rpm.

Fig. 2. Overall effect of A) water content; B) unsaponifiable matter; C) sodium + potassium + magnesium + calcium total content; and D) phosphorous content, on the variation of yield to FAME between two consecutive uses of the catalyst. Reaction conditions: $160^{\circ} \mathrm{C}$; methanol:oil molar ratio $=30$; catalyst loading $8 \mathrm{wt} \%$; time 2 hours; stirring rate $2000 \mathrm{rpm}$. $\bullet$ category- 1 fat; $\Delta$ mixed fat; $\square$ low-grade lard; $\circ \mathrm{WCO}$; crude palm oil; $\diamond$ crude soybean oil; $\diamond$ refined soybean oil.

Fig. 3. Yield to FAME from conditioned category-1 fat and mixed fat using Ar-SBA-15 in two consecutive runs. Reaction conditions: $160^{\circ} \mathrm{C} ; 30$ methanol to oil molar ratio; 8 $\mathrm{wt} \%$ catalyst loading; 2 hours reaction time; $2000 \mathrm{rpm}$ stirring rate. A) as received; B) conditioned by overnight drying at $100^{\circ} \mathrm{C}$; C) treated by washing and cationicexchanging in aqueous media with Amberlyst -15 at $40^{\circ} \mathrm{C}$ for $1 \mathrm{~h}$, followed by overnight drying at $100^{\circ} \mathrm{C}$; and D) treated by double washing and cationic-exchanging in aqueous media with Amberlyst -15 at $40^{\circ} \mathrm{C}$ for $1 \mathrm{~h}$, followed by overnight drying at $100^{\circ} \mathrm{C}$. 


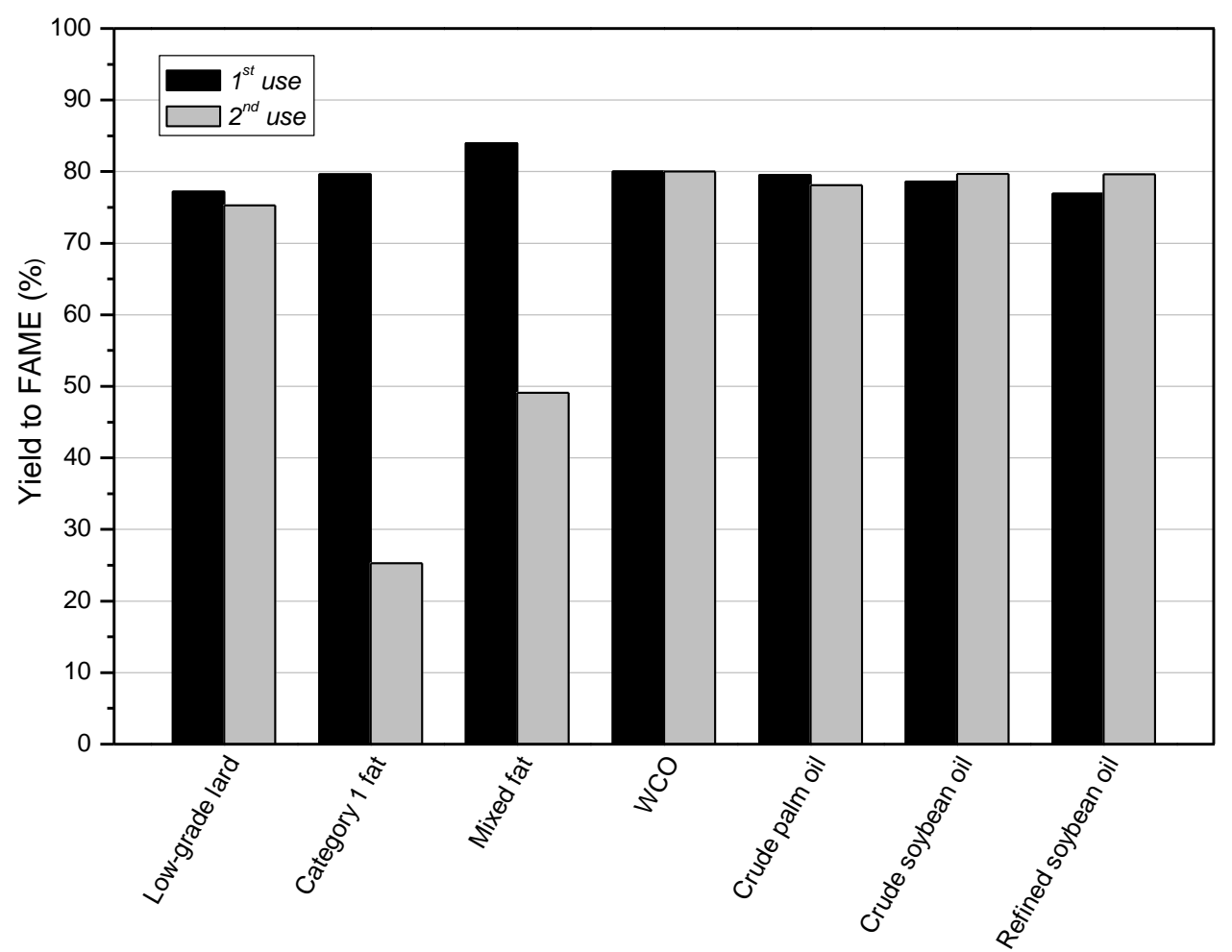

Fig. 1. Yield to FAME from different fatty raw materials using Ar-SBA-15 in two consecutive runs with intermediate catalyst washing. Reaction conditions: $160^{\circ} \mathrm{C}$; methanol:oil molar ratio $=30$; catalyst loading $8 \mathrm{wt} \%$; time 2 hours; stirring rate $2000 \mathrm{rpm}$. 

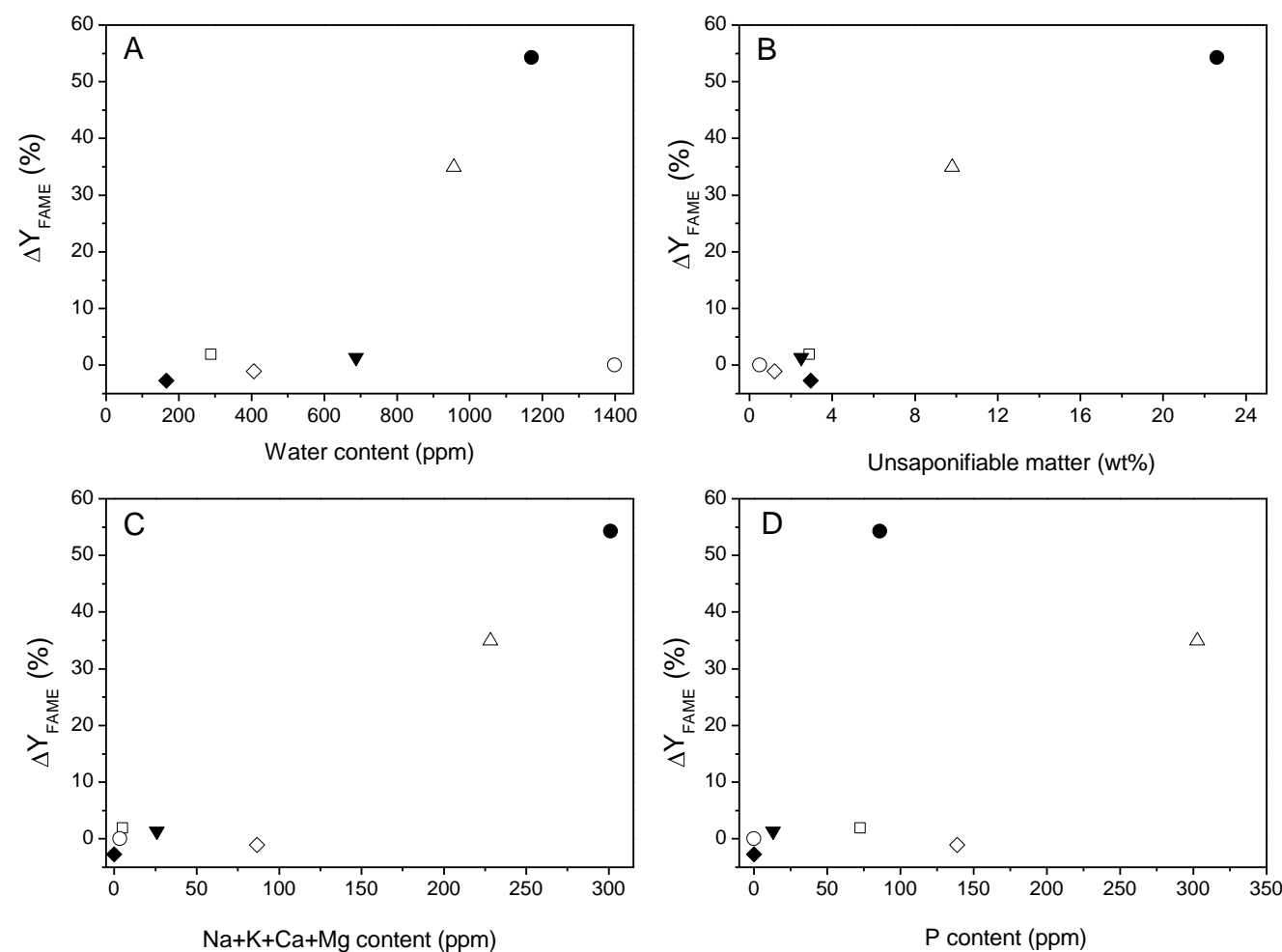

Fig. 2. Overall effect of A) water content; B) unsaponifiable matter; C) sodium + potassium + magnesium + calcium total content; and D) phosphorous content, on the variation of yield to FAME between two consecutive uses of the catalyst. Reaction conditions: $160^{\circ} \mathrm{C}$; methanol:oil molar ratio $=30$; catalyst loading $8 \mathrm{wt} \%$; time 2 hours; stirring rate $2000 \mathrm{rpm}$. $\bullet$ category-1 fat; $\Delta$ mixed fat; $\square$ low-grade lard; $~$ WCO; $\boldsymbol{\nabla}$ crude palm oil; $\diamond$ crude soybean oil; $\bullet$ refined soybean oil. 

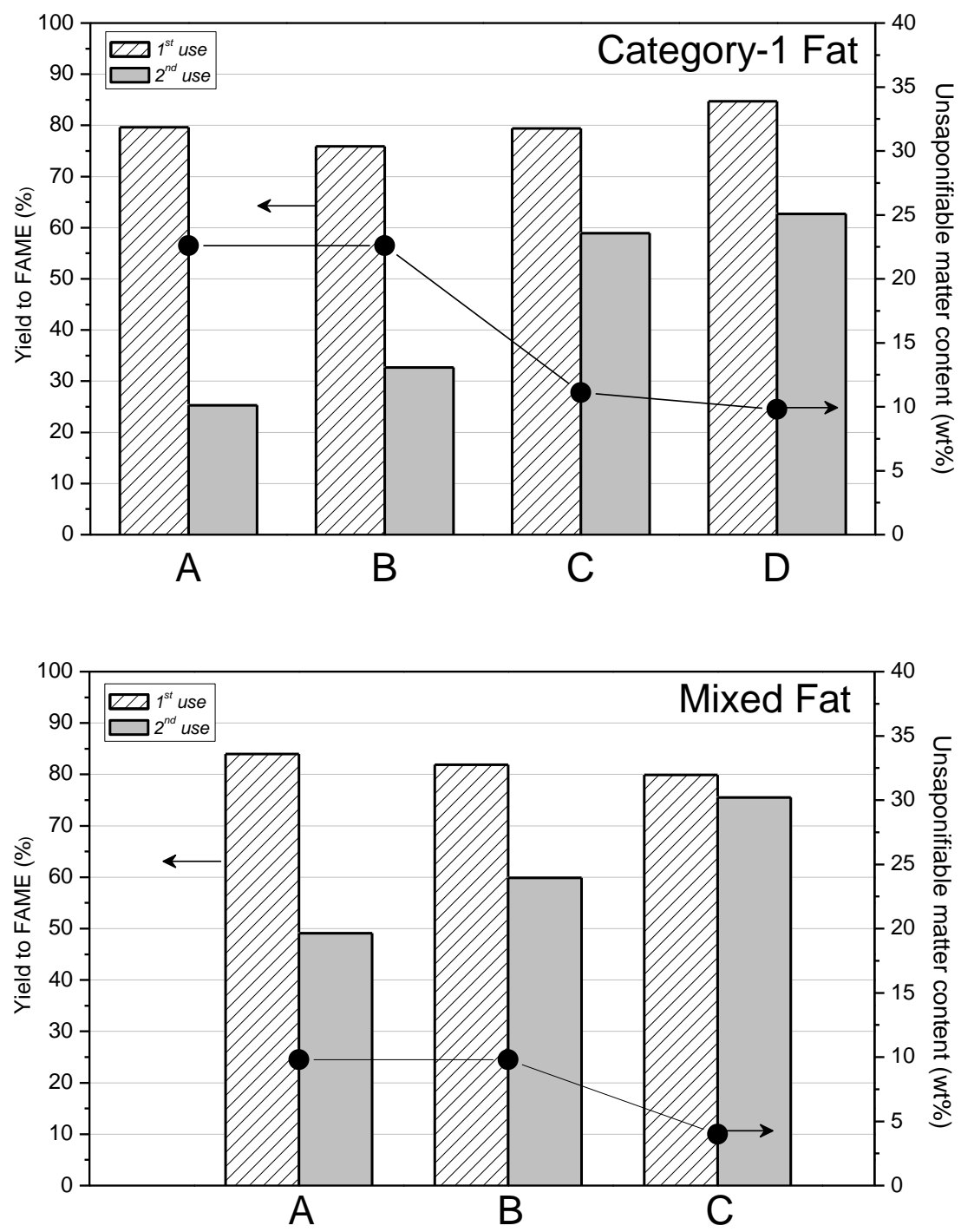

Fig. 3. Yield to FAME from conditioned category-1 fat and mixed fat using Ar-SBA-15 in two consecutive runs. Reaction conditions: $160^{\circ} \mathrm{C} ; 30$ methanol to oil molar ratio; $8 \mathrm{wt} \%$ catalyst loading; 2 hours reaction time; $2000 \mathrm{rpm}$ stirring rate. A) as received; B) conditioned by overnight drying at $100^{\circ} \mathrm{C}$;

C) treated by washing and cationic-exchanging in aqueous media with Amberlyst 15 at $40^{\circ} \mathrm{C}$ for $1 \mathrm{~h}$, followed by overnight drying at $100^{\circ} \mathrm{C}$; and $\mathrm{D}$ ) treated by double washing and cationic-exchanging in aqueous media with Amberlyst 15 at $40^{\circ} \mathrm{C}$ for $1 \mathrm{~h}$, followed by overnight drying at $100^{\circ} \mathrm{C}$. 